\title{
The European space-industrial complex: New myths, old realities
}

\section{Vasilis Zervos}

Vasilis Zervos is Associate Member at the Department of Economics, University of Strasbourg, France. He can be reached at vasilis.zervos@gmail.com.

\section{Abstract}

This article is an economic analysis of the main factors affecting the evolution of the European space industry. The critical role of the government is analyzed with regard to both military alliances and civilian intergovernmental collaboration. The analysis explores how moving from a pure public goods paradigm in collaborative projects toward a commercially-oriented, competitiveness-enhancing paradigm leads to duplication of effort and rivalries within the space agencies and other organizations. Drawing on the example of defense alliances such as NATO, the article illustrates cooperation challenges faced both at European and transatlantic levels as competition and rivalry result from inter-alliance specialization and the difficulties involved in the allocation of benefits.

$\mathrm{T}$ his article focuses on the European military and civilian space-industrial complex and various related alliances and partnerships. Space is a dual-use industrial environment both on grounds of operations and in terms of the firms that provide civilian and military space-related products and services. Considering certain market failures associated with space-industrial cost characteristics and the security implications of the relevant goods and services, there exist critically important interactions between commercial and government markets. Over the years, the fundamental nature of these interactions has remained unchanged with governments playing a leading role as regulators, customers, technology partners, and technology sharers.

Any analysis of the economics of this sector has to include geopolitics and the institutional landscape in European security and space affairs. It is therefore natural to consider European institutions such as the European Space Agency (ESA) and the European Commission (EC) as focal points. Within the industry, consolidation has resulted in just one major European space integrator (Airbus), but there also exist several satellite manufacturers, like Thales-Alenia Space (TAS) and OHB, and many other firms in the lower tiers. Despite its multinational nature, Airbus facilities and plants maintain much of their preconsolidation geography, making it a decentralized entity of a multinational character in governance and value-added.

Governments are heavily involved in the space industry as buyers, technology suppliers, regulators, and in other roles, and because of the numerous and significant market failures that overshadow the operations of the private sector. The main difference to the aerospace sector is that the "pure" space sector is (even) more dual-use and opaque than is aerospace. And while tremendous future potential exists for the industry, challenges related to the use of the outer space commons arise that may crimp the development of the space sector. Although increasing, the limited number of space-faring nations and the relatively small size of the sector - compared to its importance in defense policy and the role of national governments in itmake it difficult to analyze individual countries or themes without also considering the wider international context. ${ }^{1}$

This article presents an economic analysis of important factors affecting the evolution of the space industry in Europe. It points out how moving from the nearly-pure public good nature of space-related goods and services in collaborative projects toward project selection focusing on industry and business competitiveness can lead to duplication and rivalries within collaborating entities such as ESA. Drawing on an analogue from NATO, the article also illustrates how in future such rivalries may develop within European collaborative security organizations and programs.

The next section presents stylized facts regarding the size and structure of the industry that to a large extent define the space-industrial complex. The section thereafter examines market failures that characterize the industry, with much of the focus placed on issues regarding innovation, the "new space" concept, and the role of governments. The penultimate section considers the economics of specialization, hegemony, and alliance effects in space where military and civilian activities and behaviors differ. This is followed by a short conclusion.

\section{The space-industrial complex: An overview}

The space industry or space sector (the terms are used interchangeably here) is characterized by the presence of government-chartered space agencies that act on behalf of governments as producers of space goods and services, act as 
customers, and also as supporters of the industry. The need for the creation of space agencies like the National Aeronautics and Space Administration (NASA) in the United States or the European Space Agency in Europe emerged due to perceptions of duplication and waste associated with uncoordinated government departments (including military branches) within a given country or, in Europe's case, among countries pursuing rivalrous space activities and programs. ESA, in particular, sprang from early collaborative European efforts when it was deemed necessary to obtain the necessary scale for developing launchers and satellites. (A similar approach was taken at the industry level for joint ventures like Airbus, prior to it becoming a fully integrated company.)

ESA and NASA are considered "civilian" space agencies. In the case of the United States, the security and military dimensions of space are placed in the care of its Department of Defense (DoD) and enjoy budget appropriations on par with NASA. For Europe, no such equivalent with military space activities exists. Exceptions, even at the operations level, are negligible. For one thing, membership of sovereign states in ESA and the EU differ and despite calls for ESA to turn into a space agency under the aegis of the European Commission (EC) - the EU's executive body - the relation between them is still developing, the idea being that the EC would assume operational control of space systems and services and act as a partner (in effect, as both, principal and customer) to ESA. ${ }^{2}$

In contrast to the competition-enhancing nature of the $\mathrm{EC}$, ESA operations are based on a traditional inter-governmental model whereby national inputs to a collaborative scheme are matched by equivalent-value contracts to the national industry. This institutionalized juste retour (fair return) process is the ESA's main decisionmaking and implementation characteristic. (Similar approaches linking regional industrial returns with high-level space programmatic decisions are found in the lobbying activities and political representation in the U.S. Congress where local political representatives seek territorial returns and value-added from federally-funded space activities.)

Space agencies are expected to coordinate and consolidate space efforts and be a point of contact for the space industry. Large parts of the setting of space objectives, and of program and prime contractor selection, are determined by power struggles. This is crucial for an understanding of European space efforts as ESA's initial mandate pertained to the development of technology - and to the pooling of the resources of the various nations that comprise it - alongside the advancement of science. A good example of this is the development of the Galileo and Copernicus programs. Analogous to the United States' GPS/NAVSTAR system, Galileo started out as a public-private partnership to build a
This article presents an economic analysis of important factors affecting the evolution of the space industry in Europe. It points out how moving from the nearly-pure public good nature of space-related goods and services in collaborative projects toward project selection focusing on industry and business competitiveness can lead to duplication and rivalries within collaborating entities such as the European Space Agency. Drawing on an analogue from NATO, the article also illustrates how in future such rivalries may develop within European collaborative security organizations and programs.

satellite-based, commercially-oriented geopositioning system. Following significant delays, lack of interest by the private sector to engage in operations, and security challenges given NATO's support of the U.S. GPS system, Galileo was reprofiled from a private-public partnership into a public entity, with the public sector fully funding the program's R\&D and operations. $^{3}$

Economies of scale and scope are extremely important in manufacturing products (e.g., satellites, launchers, ground stations, and equipment) and providing related services (e.g., telecommunication, remote-sensing information, meteorology, positioning and navigation signals). Respectively, product and service development are complemented by economies of learning and joint economies of learning. But savings from such economies are limited in that most space companies are nationally confined and, like military equipment, subject to export restrictions. In countries like the U.S. this falls under the rubric of International Trade in Arms Restrictions (ITAR). In Europe, under the Wassenaar Agreement and under national legislating, the situation has come to the point where industry associations are openly calling for a streamlining of procedures, at least for the intra-EU trade. ${ }^{4}$

Military and security concerns have led governments to support space autonomy as a critical objective. Consequently, a limited number of products are produced by many national industries, leading to fragmentation and multiplication of effort. Product manufacturing is subject to high R\&D intensity and high fixed costs, and production methods are customized in nature rather than mass produced. Mass production is the exception, with the best examples occurring in Germany during world war two (e.g., the A4 or V2) and the Soviet Union/Russia (the Soyuz). In the Soviet Union, the high demand for expendable launch vehicles came about because of the then-limited image recording technologies (prior to the displacement of film by digital methods) requiring remotesensing satellites to carry film onboard which, upon reentry, would be retrieved by intelligence agencies. The satellites' life time therefore was very short but, economically, made mass production of launch vehicles feasible. In time, of course, 


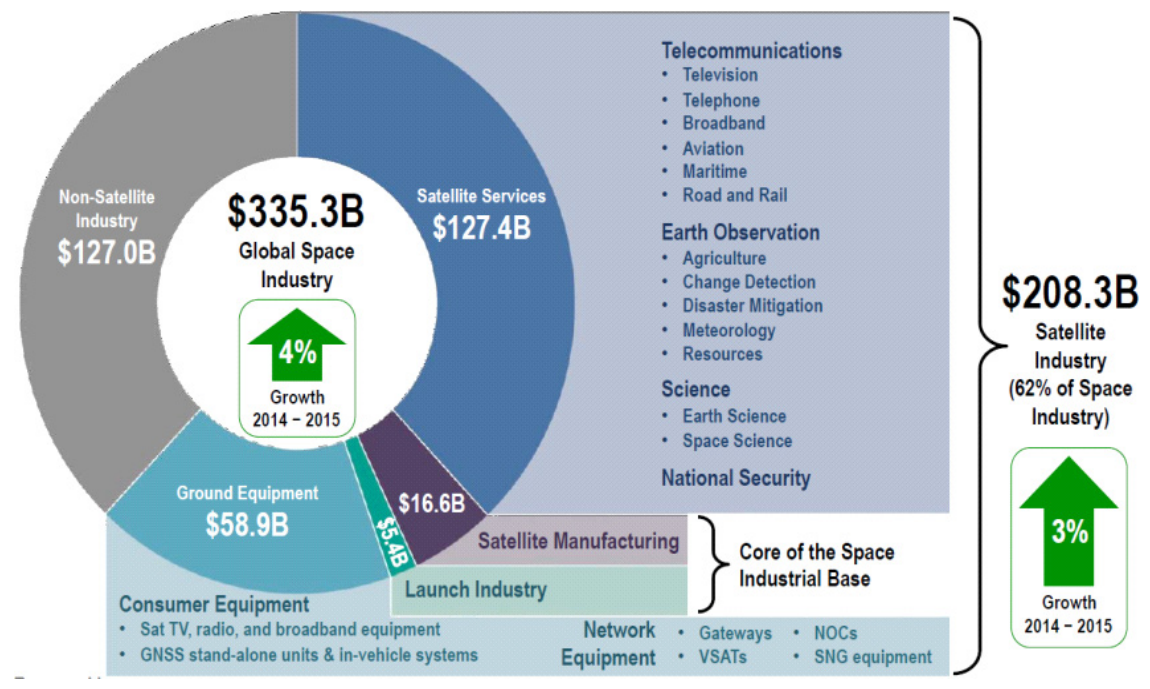

Figure 1: The global space industry. Source: SIA (2016).

digitization and encrypted image transmission led to changes in satellite technologies that shrank the relevant demand for launchers. ${ }^{5}$

Regarding space-based services, the most developed pertain to telecommunications. During early satellite development, Intelsat was formed, an intergovernmental consortium comprised, for the most part, of national telecommunication monopolies. Its natural monopoly status for fixed-satellite communications reflected significant scale effects. With technological change and the commercialization of telecommunication services and organizations, the consortium lost its natural monopoly status and became but one of today's major telecommunication service providers such as SES and Eutelsat. $^{6}$

Perhaps the industry's most visible activity is launch vehicle manufacturing and satellite delivery services, followed by satellite manufacturing and ground support equipment and supplies. Yet launch vehicles account for but a small fraction of turnover. In 2013, this was USD5.4 billion worldwide, compared to an industry total of nearly USD260 billion. Indeed, the definition of the space sector is itself neither uncontroversial nor uniform, as shown in Figure 1. Collecting space industry-related data is challenging because of the limited number of standard industrial classification codes assigned to the sector and because space business is often embedded in defense-aerospace consolidated figures in Europe and in the United States. International data collection also suffers because different classification systems are in use and because of security considerations and the noncommercial nature of many space activities. Effectively this means that aggregation and cross-country comparisons, for instance for purchasing power parity measures, become problematic. $^{7}$

In the early 2000s, following the end of the cold war, the U.S. industry consolidated into two main space integrators, Lockheed Martin and Boeing. Meanwhile in Europe, Airbus (satellites and launchers) emerged along with TAS (satellites), OHB System, and others. European consolidation took place in two discrete steps. First, national champions emerged in countries like Germany, Spain, and the U.K. Second, these then merged into cross-national corporate entities (e.g., the French-Italian TAS, the French-German-Spanish-British Airbus' Space Systems, and the German-Italian OHB System). Despite this, the companies mostly maintained their national production plants. Due to technical differences among satellites, launchers, and aircraft, other countries, like Russia, have kept their space and aerospace businesses separate. ${ }^{8}$

Airbus and TAS employ about 60 percent of the total space industry's labor force (about 38,000 employees in total versus an estimated 250,000 in the U.S.). Another 20 percent are distributed across OHB System, RUAG, Telespazio, and Safran, with the remainder dispersed across a number of smaller firms. Apart from the key manufacturers, launch-service providers like Arianespace and leading telecommunication service providers like Eutelsat and SES/O3B form the core of Europe's space-related industry, notwithstanding the fact that institutions like ESA maintain their own manufacturing and technical facilities (ESTEC), as is habitually the case in the space sector. Arianespace's main product line is the heavy-lift Ariane 5 launcher (manufactured by Airbus-Safran Launchers, a joint venture between Airbus and Safran) and the lightweight Vega, with the medium-weight Soyuz-Frigate (a Russian-based launcher) complementing the spectrum of launchers from French Guiana's launchpad facilities. Intelsat and SES/O3B, based in Luxembourg, are the leading civilian telecommunication service providers, followed by Inmarsat, Eutelsat, and others. ${ }^{9}$

Leading telecommunication service providers, like SES, increasingly carry government payloads of a dual-use nature onboard their satellites. The dual-use nature of satellite telecommunications is illustrated by the use of private finance initiatives - which despite their name are a form of publicprivate partnerships. For example, Paradigm Secure Communications (currently owned by Airbus) was set up to 
own and manage the U.K.'s Skynet military telecommunication system and allocate spare capacity to commercial markets, while also serving NATO needs. The entry of Airbus into the telecommunications service sector, and the links between civil telecommunication operators and military payloads, highlight the integrative nature of the main companies, with fuzzy limits between manufacturing and service provision and between military and commercial work at the corporate level. This is not unique to telecommunication services. Remote sensing, for instance, also sees expanding business for imaging value-added services taken up by service subsidiaries of satellite manufacturers. Similarly, remote satellite servicing extends to areas of specialization with, presently, a French dominance in optical systems and a German focus on radar technologies. ${ }^{10}$

All this suggests that in regard to manufacturing the European space industry is in the midst of further changes in its corporate governance regime-led by heightened competitiveness in global launching services - while still being heavily influenced by ESA's juste retour approach whereby national delegations at ministerial conferences support programs and allocate appropriations by considering industrial competitiveness factors along with country-based security and social needs. This has profound implications for the choice and processes of the programs followed, and also for the industrial structure, conduct, and performance of firms dependent on collaborative institutions and alliances.

The government-institutional framework and its alliance and strategic implications are examined next.

\section{Market failures}

With the end of the cold war, an initially reduced demand for military space applications saw a move toward civilian arenas, spearheaded by efforts to commercialize and develop new space markets and activities. The example of Intelsat was described earlier, but the flagship programs of the early 1990s were associated with space-based mobile telecommunications whereby (prior to the advancement of terrestrial networks) satellites were the driving force in mobile telephony architectures. The bankruptcy of the Iridium cellular satellite network in the early 1990 s proved to be a turning point in the fortunes of satellite-based communications. The underlying technical challenges associated with direct-to-satellite links (energy requirements, line-of-sight), pressures for national control of telecommunications, and the economic return provided by auctioned frequencies all played key roles in the decline of satellite-based mobile communications and the subsequent mushrooming of terrestrial networks.

The recent emergence, predominantly in the United States, of so-called "new space" endeavors driven by an international class of high-net worth individuals such as Jeff Bezos (U.S.), Elon Musk (South Africa), and Richard Branson (U.K.), alongside traditional space integrators, has renewed interest in the commercial development of space through civilian applications, particularly the exploration and colonization of celestial bodies. Some of these endeavors reflect infant industry characteristics in that despite private funding directed to the development of new space capabilities like launchers, the main customer and supporter of technological know-how is the public sector. The role of government is therefore instrumental and deserves attention. Concentration in the industry, resulting from economies of scale and scope, is limited by government security concerns in a manner similar to the defense industry, but with the same companies serving commercial markets and operations of critical importance to the overall economic network. In addition, spin-offs from space programs are seen as vital to lead to high-tech economic growth and development, while space assets are crucial in supporting networks of high economic value and also for security/military operations. Space-based positioning signals are supporting digital-age applications found in logistic chains and commercial devices in their unencrypted form, while the encrypted, military ones are instrumental for precision military operations alongside remote sensing and telecommunication information that form the backbone of command, control, communication, and intelligence systems. ${ }^{11}$

Such externalities and public good effects, as well as the security concerns, provide justification for governments to support the industry. Efforts to commercialize space capabilities, technologies, and assets depend to a great extent on governments to create demand conditions that will support newcomers, given the high minimum efficient scale found in production. Thus projects tend to be privately funded but government dependent, following a national autonomy model rather than an international business one. For example, Space $\mathrm{X}$ - a prominent firm - is calling for a bigger market share of U.S. government payloads based, in part, on an argument of U.S. autonomy and independence from Russian rocket engines supplied to its U.S. competitors.

Plans of internet companies such as Google and Facebook to build large constellations of satellites that would operate in layered orbits to provide access to internet and communications on a global scale would seemingly act in competition with existing architectures (SES/O3B and others). This carries internet governance implications, but is otherwise similar in nature to the Iridium experience mentioned before. Yet nationally confined industrial partnerships with firms that would develop such networks could or would also render 
security services - as described by the military-Operationally Responsive Space (ORS) or other relevant doctrines - at lower cost while offering increased security and overall economic benefits. $^{12}$

In dealing with the industry, governments and their space agencies tend to act in what can be characterized as a two stage process. In the first stage, general decisions and appropriations are determined. Agency and industry share similar objectives in government bids. In the second stage, however, the space agency is supposed to share the government's objectives of rent control and cost minimization in industrial contracts. This is a key element of the space-industrial complex and reflects principal-agent relations that have developed over time.

In Europe, the intergovernmental nature of ESA presents significant challenges. In view of the high R\&D-to-production cost ratio and the typical low technology-readiness levels at the feasibility stage of space projects, fixed-price contracts would seem unsuitable compared to cost-reimbursement ones. The latter would necessitate a structured monitoring mechanism similar to the those found in U.S. federal procurement policies such as the Earned Value Method System. In the past, however, fixed-price types of contracts have been extensively used by ESA, to be modified de facto by Contractual Change Notices in later stages of the contract life cycle. To avoid this high-transaction cost practice, novel contractual mechanisms have been developed. One of these is the Ceiling Price to be Converted to Fixed Price-type of contract. It contains a maximum price liability clause, followed by a fixed-price contract for the later, more mature, stages of a project's life cycle. The political objectives underlying the negotiations within ESA's ministerial council-comprised of representatives of all member states (over 20 countries)-would, or should, have much to do with the challenges associated with monitoring cost-reimbursement contracts. More importantly, the process is likely to give rise to significant bureaucratic power in view of the inflexibilities associated with the infrequency of meetings and also with the size of the governing ministerial body. Added to this is the lack of transparency, in terms of public information disclosure, as all member states would have to agree for the relevant figures and information to be released. ${ }^{13}$

The importance of ESA's role in the European spaceindustrial complex has become clearer with the recent policy of institutionalizing its involvement in the selection of lowertier contractors by the prime in the contracts it manages. While this has allowed ESA to control the distribution of value-added according to the juste retour principle along the value chain of the industry, this arrangement is expected to raise issues of lack of accountability (within a principal-agent framework) of the prime contractor. $^{14}$

Public policy clearly is instrumental in determining the structure, conduct, and performance of the industry. This is apparent in Europe's success in commercial launchers (which has overshadowed failures in its space programs, like Hermes), which resulted from an aggressive European presence in commercial markets and a clear export orientation. This was borne out of necessity as the European markets were limited in size, relative to the United States, and an inter-NATO alliance specialization that had been taking place. Given the cost characteristics discussed earlier, European industry in the commercial space markets was at a disadvantage relative to more experienced players such as the U.S. and Russia. Policy and incentive alignment seem to have been critical in reversing this. Specifically, the U.S. policy of supporting the Space Shuttle (STS) in its early stages of operation at the expense of expendable launch vehicles (U.S. Delta, Atlas launchers) led to a period where commercial markets were best serviced by the most suitable expendable launch vehicle that remained on the market, the European Ariane 4. As the U.S. space industry enjoys a lucrative domestic military and civilian market, the country has less of an incentive to participate in the competitive commercial markets than its European counterparts. ${ }^{15}$

In recent decades, space agencies have included in their mandate an objective concerning the enhancement of industry competitiveness in commercial markets. This has led them to develop market-enhancement institutions for relevant technologies, even in the absence of a proper market mechanism. Thus, for example, NASA and ESA are involved in the transfer of technology and play a supporting role for entrepreneurial activity through activities such as licensing, release of experienced technical personnel and facilities to private industry, and specialized incubation centers to support innovation and entrepreneurship. As part of defense, military space budget appropriations are covered under the DoD budget in the United States, while in Europe, national space agencies and multilateral programs are of a more fragmented nature. Thus, ESA's enhanced skills and institutional facilitation led it to take on, along with the EC, a more defense-oriented role through security-related programs and projects, with resulting governance and access issues. Increasingly, ESA thus finds itself at the center of economic activity, much of which it directly controls, including the selection and evolution of winners and losers, often beginning with any project's start-up stage. Thus the public sector, through its bureaucracy, determines the structure, conduct, and performance of the sector throughout the supply chain, along with its overall development path. 
Specialization in alliances: Military space and hegemony As noted, much of the consolidation and centralization of space efforts have been driven by collaboration at governmental level. It has also been driven by action at the industry level, to avoid duplication and to maintain efficiency. The resulting alliances and institutional partnerships like ESA, NATO, or within the EU, while necessary developments, do not always work as expected. An alliance can be compromised by hegemonic behavior within a group and may enhance autonomy rather than specialization. Rivalries and duplication can result. This is evident in the development of European strategic capabilities in areas traditionally served by U.S. assets within the NATO alliance (space-related, mostly, such as geopositioning services like Galileo). While supported on the grounds of commercial competitiveness, they have been controversial. As Europe develops its security capabilities, frictions arise within single-body institutions like ESA as a result of domestic policy pressures and the different security concerns of the constituent countries. This adds systemic costs of partnerships to the generic collaborative costs in projects. ${ }^{16}$

Allowing for strategic interdependency within alliances, behavior that considers others' welfare as affecting one's own, complicates economic analysis. For example, when Europe's Galileo system introduced its civilian services, the cost of commercial market space-based, radio-navigation positioning services fell. Thereupon, the U.S. abandoned its policy of quality-restricting its military GPS signal for commercial use. Altogether, this not only significantly decreased costs for civilian users who did not use terrestrial signals or other techniques to augment positioning accuracy but (probably) also increased U.S. military costs. The reason is that what matters for the U.S. military is its position relative to a rival who is now assumed to be enjoying a commercial-quality signal. This can be jammed, but at an additional cost to the U.S. military. Or, as two analysts commented: "From a techno-nationalist, geostrategic perspective Galileo is an indicator of power. But it does not, nor is it intended to, place Europe in competition with the USA as a global military power. It does, however, impinge on a strategically important area in which the USA has previously dominated." 17

Within NATO, overlapping competencies caused by hegemonic instability and challenges lead to duplication and potential rivalries. On the one hand, while some space assets are not entirely of a pure public goods nature, significant discretion remains in regard to sharing space-based assets and related information. On the other hand, going one's own way results in duplication costs and challenges inter-alliance specialization that can lead to rivalries within. European calls for autonomy and independence from reliance on U.S. launchers were behind the development of European launch activities and the early development of the Ariane family of launchers, but the more recently development of Galileo was based on arguments regarding signal security, i.e., not having to rely a U.S. GPS system for European security and economic activity. This led NATO to affirm its exclusive use of the U.S. GPS as its positioning service provider, with Galileo used for related services on frequencies initially intended to overlap with the U.S. military ones. Thus the U.S. would find it challenging to locally jam the Galileo signal without also compromising its own capabilities. This "case study" indicates how specialization is critical for alliance performance and stability, yet also benefits the participants.

By analogy, the ESA experience was based on the development of technology and exploration of space with data and goods of a public good nature among the participating members. The now-expanding nature of ESA into a promoter of economic benefits to industry and developer of security systems will challenge this public good nature. Development of business incubators and selection of programs based on commercial returns and industrial benefits to member states inevitably will lead to resource allocation patterns that skew benefit distribution among members. This, in turn, carries implications for the affected industries that are competing in commercial markets. By introducing commercial/industrial enhancement and competitiveness objectives both at the level of program selection and at the level of technology diffusion, new rivalries may emerge while specialization becomes critical for the commercial competitiveness of member states. This may, again, lead to cost duplication and rising instability as already experienced within NATO.

\section{Conclusion}

As networks and systems in the broadly-understood security and commercial sectors continue to grow, outer space is becoming ever more important to earthly commerce and governance. An extensive, ongoing discussion surrounds the "new space" initiatives in the United States, how they would affect efficiency and what would be their implications for the wider space sector. At least some of the impetus for these developments has been the speed of developments in space technologies and capabilities from space-faring nations in general and new actors, such as China, Russia, India, and Japan in particular. Historically, European space efforts are characterized by military reliance on the alliance with the U.S. within NATO. At the same time, civilian and security developments are taking place at the EC and ESA-levels, complementing commercial space activities and orientation. Interestingly, Europe has been able to show more autonomous 
behavior within the NATO alliance through its Ariane program and, more recently, through its partnership, with China, in the early stages of the Galileo program and, with Russia, in the marketing of Soyuz. (Among others, Russia and China also are engaged in developing partnership with countries such as South Korea for launching and satellite technologies.) The intra-European dynamics are important to the economic health of the sector, but the processes to choose partnership arrangements and the selection of future programs are neither transparent nor obvious in terms of their dynamics. Given the implications for the relevant industries, and also for the wider economic and security arenas, further analysis of the inter-European (ESA) and inter-NATO alliance specialization is crucial. $^{18}$

In sum, this article has examined the space-industrial complex. The intra-European dynamics (e.g., ESA and the industry) and inter-alliance dynamics (i.e., NATO) are related and at a crossroads in view of developments both within Europe - as the EC becomes more engaged in space-security and other matters - and as global partnerships and heightened capabilities emerge. Reconciling the tensions among military, commercial, and wider economic objectives, where efficiency is considered as more important than relative political gains, is an important focus for future research. This is made difficult by the role of the public sector and the lack of transparency in the space-industrial complex. Finally, inter-alliance implications for efficiency and competitiveness of the contributing partner industries, whether within inter-governmental space agencies like ESA with significant security-enabling undertakings, or defense organizations such as NATO, need to be better understood.

\section{Notes}

The author thanks the editors and an anonymous reviewer for helpful comments and suggestions. The usual disclaimer applies.

1. Defense policy: See, e.g., NAS (2016) for the security challenges and implications of space. Besides defense criticality, for space-faring nations space and aerospace are also perceived as economically critical, including export performance, with interactive dynamics between these two areas (see Hartley, 2014; O’Neil, et al, 2016; TehranTimes, 2016).

2. Negligible exceptions: Whereas civilian space collaboration in Europe is institutionalized at the EC and ESA levels, collaboration in military space activity is episodic and fragmented on account of changing time-limited partnerships at the bilateral and multilateral levels (see, e.g., Pasco, 2009). Notable military space programs and budgets in Europe are those of France and the U.K. (The anticipated withdrawal of the U.K. from the EU might lead it to reinforce its space capabilities and industrial base, both at national and collaborative levels.) The EC and ESA are increasingly involved in security-related space arenas, while evolving their roles and relations within Europe and at a global level. Recent calls for the establishment of a "Govsatcom" partnership have been made (Henry, 2016).

3. ESA's initial mandate: ELDO, the European Launcher Development Organization, and ESRO, the European Satellite Research Organization, merged in the 1970s to form today's European Space Agency. NATO's support: Zervos and Siegel (2008). Copernicus: Until recentluy, Copernicus was known as Global Monitoring for Environment and Security (GMES). It comprises the European contribution to the Global Earth Observation System of Systems (GEOS). Copernicus is a partnership between the EC and ESA and is an Earth observation program using data from about thirty satellites mostly related to remote sensing, scientific, meteorology, and others purposes of military, civilian, and commercial pedigrees.

4. Economies of learning: See Zervos (2001). Streamlining: See EC (2016).

5. Expendable launch vehicles (ELVs): They are one-off launch systems employed for space transportation purposes such as satellite payloads. This is similar to intercontinental ballistic missiles (ICBM) where the payload is one or more warheads. Based on ICBMs, EVLs exploit economies of scale and avoid R\&D duplication. Elements of ELVs have historically been re-used in the case of manned spaceflight (, e.g., the capsule module). More recently, modules are being used to reduce launch costs by private companies like SpaceX, Blue Origin, and others. Fully reusable launch vehicles (RLVs) have not yet been widely developed, but semi-reusable ones have, like the space shuttle system (STS), Buran, and the more recent unmanned X-37. Custom versus mass production: In contrast, the European Arianespace's Ariane 5, for example, has a serial production capacity of about 7 to 8 launchers per year.

6. Natural monopoly: Snow (1987).

7. Turnover: OECD (2014). Definition of space industry: See Zervos (2001) for a review of space industry-related data and figures. Standard industrial classification code: Space industry definitions vary, with space-based services sometimes included in the estimation. For example, positioning services from GPS signals can be used to qualify terminal applications like bank ATMs or mobile phone devices.

8. OHB System: Originally, Otto Hydraulik Bremen $\mathrm{GmbH}$ (OHB). Today, the name of the overall group is OHB SE, with a space division and an aerospace and industrial products division. It is still headquartered in Bremen, Germany.

9. Employment numbers: Eurospace (2016). Arianespace: As of December 2016, Arianespace is majority-owned by Airbus and Safran, with the passing on of shares previously held by the French national space agency, CNES. See Arianespace (2016). 
10. Dual-use: See Defence Industry Daily (2015). A similar fusion among commercial, military, and government civilian services is experienced in the less commercially developed Earth observation market (i.e., remote sensing) through relevant partnership arrangements and also through reliance of military services on commercial entities (e.g., U.S. Digitalglobe). Airbus includes such services in relevant satellite constellations, while in the U.S. the policy has been to promote commercialization of remote-sensing data services since the 1980s through various acts of law (e.g., the Land Remote Sensing Commercialization Act of 1984).

11. High-net worth individuals: The entrepreneurial approach to space program development now has extended to Europe and other countries, e.g., China, where individuals contemplate investing in space technologies and development (de Selding, 2016). Overall economic network: Commission (2001).

12. ORS: The U.S. DoD's operationally responsive space doctrine calls for fast response times in space development and the replenishment of assets in case of a "space Pearl Harbor." This carries profound dual-use implications (see Butler, 2015; ISU, 2010; Commission, 2001).

\section{Principal-agent relations: Zervos (2001).}

14. Lack of accountability: Zervos (2015).

15. Export orientation: Export contracts resulted also from the need to maintain autonomous access to space for defense (satcom, Earth observation) and the need to preserve industrial and technological competencies for deterrence when military production was stopped. Competitive markets: Zervos (2001).

16. Driven by collaboration: In addition, given the public perception of space as a civilian technological enabler, the space sector has also been able to act as a political mechanism to enhance security and cooperation among political adversaries (e.g., the Apollo-Soyuz docking in the 1970s). Duplication and rivalries: In that respect, rivalrous, or precautionary behaviors, even within alliances, would call for duplication of assets and development of autonomous capabilities. Systemic costs: Hartley (2014).

17. Galileo: The high-precision signal that is commercially available in mobile consumer devices mentioned earlier is a spin-off from an all-military positioning program that started in the U.S. (NAVSTAR-GPS, also initiated in the USSR as Glonass; both are operational today) several decades ago. Until the 2000s, the military exercised selective availability for civilian purposes. This was to prevent potential adversaries enjoying the same level of information as the privileged encrypted military signal. To a lesser degree, the difference in signal properties and quality continues to this day. Selective availability and control over commercially sensitive assets was the backbone of the European argument to develop its own commercially-oriented system, Galileo. For analysis, see Zervos and Siegel (2008). Jamming: Clearly, in evaluating the relative costs and benefits from commercializing signal technologies, the economic benefits from accurate positioning for the whole economy are expected to create wealth, and tax revenues. These benefits might well compensate for the cost of jamming or other perceived losses of positioning-related military advantages over adversaries. Quote: Johnson-Freese and Erickson (2006, p.18).

18. Extensive, ongoing discussion: See, e.g., NASA (2014); ASAP (2014). Soyuz: Arianespace is the only major company that is launching foreign launchers from its launch center in Kourou, in French Guiana, having built specialized facilities and purchasing batches of Soyuz to this purpose. Dynamics: ESA follows a decisionmaking approach based on a ministerial conference where relevant programs and budgetary appropriations are decided. However, in terms of following up on programs, decisions and processes, besides limited transparency (certainly, as compared to NASA) on contracting information, there is also limited exposure of significantly delayed, or cancelled programs like Galileo or Hermes. Galileo experienced significant cost overruns and delays, but also saw the withdrawal of private sector actors and the reprofiling of the venture as a public partnership with the EC. As for Hermes, the famous Ariane 5 program that appears to be rather uncompetitive in terms of price and cost for commercial operations. Initially built to support a manned ESA space program with a small scale "space shuttle," called Hermes, it was eventually cancelled. The U.S. is relying on its Government Accountability Office (GAO) to control processes and ensure transparency, with program decisions to cancel or approve dependent on the political process. In Europe, ESA has instigated the institution of the inspector-general, but with minimal public transparency owing to the intergovernmental nature of ESA.

\section{References}

[ASAP] Aerospace Safety Advisory Panel. 2014. NASA Aerospace Safety Advisory Panel Annual Report. https://oiir.hq.nasa.gov/asap/documents/2014_ASAP_An nual_Report.pdf

Arianespace. 2016. "Governance of Arianespace: Airbus Safran Launchers Becomes the Majority Shareholder." Corporate Press Release. http://www.arianespace.com/ press-release/governance-of-arianespace-airbus-safranlaunchers-becomes-the-majority-shareholder/

Butler, A. 2015. "USAF Operationally Responsive Space Office Could Oversee Next SSA, Weather Sats." Aviation Week. 12 February 2015. http://aviationweek.com/space/ usaf-operationally-responsive-space-office-couldoversee-next-ssa-weather-sats

Commission. 2001. "Report of the Commission to Assess Unites States National Security Space Management and Organization." Washington, D.C.: Commission to Assess United States National Security Space Management and Organization. http://www.dod.gov/pubs/space20010111. html

Defence Industry Daily. 2015. "Skynet 5: UK MoD's Innovative SATCOM Solution.” 16 September 2015. http://www.defenseindustrydaily.com/skynet-5-uk-modsinnovative-satcom-solution-06244/ 
de Selding. 2016. "New Chinese Commercial Launch Company Advertises High Launch Rate, Low Price." Spacenews. 29 November 2016. http://spacenews.com/ new-chinese-commercial-launch-company-advertises-high -launch-rate-low-price/

[EC] European Commission. 2016. "Dual-Use Export http:/ec.europa.eu/trade/import-and-export-rules/export-f rom-eu/dual-use-controls/index_en.htm

Eurospace. 2016. “A Space Strategy for Europe.” Position Paper. Paris: Aerospace and Defence Industries Association of Europe (ASD)-Eurospace. http://www.eurospace.org/ Data/Sites/1/eurospacepositionpaper_spacestrategy.pdf

Hartley, K. 2014. The Political Economy of Aerospace Industries. Cheltenham, UK: Elgar. https://doi.org/10.4337/9781782544968

Henry, C. 2016. "European Commission Official Presses Govsatcom Case." SpaceNews. 8 December 2016. http://spacenews.com/european-commission-official-pres ses-govsatcom-case/

[ISU] International Space University. 2010. "Space and Responsive Systems." Student Report. ISU Strasbourg. https://isulibrary.isunet.edu/opac/doc_num.php?explnum $\mathrm{id}=84$

Johnson-Freese, J. and A. Erickson. 2006. "The Emerging China-EU Space Partnership: A Geotechnological Balancer." Space Policy. Vol. 22, No. 1, pp. 12-22. https://doi.org/10.1016/j.spacepol.2005.11.001

NASA. 2014. Emerging Space. https:/www.nasa.gov/sites/ default/files/files/EmergingSpaceReport2014.pdf

[NAS] National Academies of Sciences, Engineering, and Medicine. 2016. National Security Space Defense and Protection: Public Report. Washington, D.C.: The National Academies Press.

[OECD] Organization for Economic Cooperation and Development. 2014. The Space Economy at a Glance. Report. Paris: OECD. http://www.oecd.org/sti/the-spaceeconomy-at-a-glance-2014-9789264217294-en.htm

O’Neil, B., S. Norton, L. Levesque, C. Dougherty, and V. Genanyan. 2016. "Aerospace and Defense Economic Impact Analysis.” HIS Report for the Aerospace Industries Association. https://www.aia-aerospace.org/report/ aerospace-and-defense-an-economic-impact-analysis/

Pasco, X. 2009. "A European Approach to Space Security." Cambridge, MA: American Academy of Arts and Sciences. http://www.amacad.org/publications/spaceEurope.pdf

[SIA] Satellite Industry Association. 2016. "State of the Satellite Industry Report." Satellite Industry Association Report. Bethesda, MD: Futron Corporation.

Snow, M. 1987. "National Monopoly in INTELSAT: Cost Estimation and Policy Implications for a Separate System Issue." Telemetics and Informatics. Vol. 4, No. 2, pp. $133-150$. https://doi.org/10.1016/0736-5853(87)90007-4

Tehran Times. 2016. "Iran Air, Boeing Sign \$16.6b Deal.” 11 December 2016. http:/www.tehrantimes.com/news/ 409019/Iran-Air-Boeing-sign-16-6b-deal
Zervos, V. 2001. "The Economics of the European Space Industry." D.Phil. Thesis. University of York. Department of Economics. Centre for Defence Economics. York, UK.

Zervos, V. and D. Siegel. 2008. "Technology, Security and Policy Implications of Future Transatlantic Partnerships in Space: Lessons from Galileo.” Research Policy. Vol. 37, No. 9, pp. 1630-1642. https://doi.org/10.1016/j.respol.2008.06.008

Zervos, V. 2015. "European Policies and the Space Industry Value Chain." Conference paper. 19th Annual International Conference on Economics and Security. Grenoble, France. 